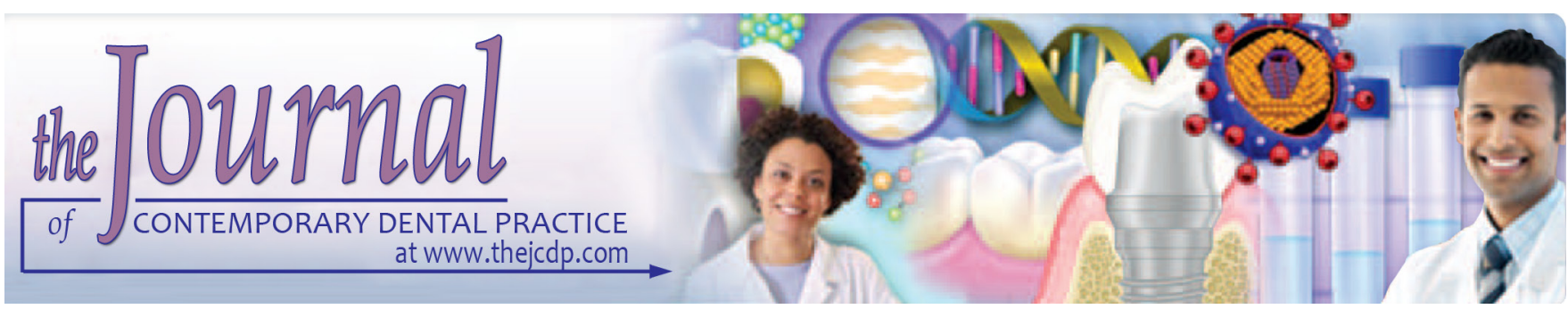

\title{
Perception of Facial Esthetics by Laypersons, Dental Assistants, General Dental Practitioners and Dental Specialists
}

\section{Alhammadi MS}

\section{ABSTRACT}

Aim: This study sought to assess perception of facial esthetics by laypersons and dental professionals.

Materials and methods: Three standard photographs were digitally manipulated involving three facial characteristics; facial symmetry, facial profile and facial vertical proportions. A sample of 465 [142 laypersons (LP), 97 dental assistants (DA), 152 general dental practitioners (GDP) and 74 dental specialists (DS)] evaluated the standard and the manipulated images on a visual analogue scale ranging from 1 (the less pleasant image) to 5 (the standard image). The responses were analyzed using Kruskal-Wallis and Mann-Whitney tests. A $p$ value of $<0.05$ was considered significant.

Results: The overall score was $61.29 \pm 16.19 \%$ with no statistical difference by gender. GDP showed significantly higher perception score than LP, DA and DS did. Regarding the individual facial esthetic components, females showed significantly better perception for "facial profile", while males showed significantly better perception for "facial symmetry" and "facial vertical proportions". Facial symmetry and facial vertical proportions were perceived differently with the higher perception score for the GDP and the lowest perception scores were for LP.

Conclusion: Remarkable variations do exist with regard to facial esthetic perception by LP, DA, GDP and DS, with GDP showed more favorable perception.

Clinical significance: Perception of facial esthetics by laypersons and dental practitioners with a different level of dental

Department of Preventive Dental Sciences, Division of Orthodontics and Dentofacial Orthopedics, College of Dentistry, Jazan University, Jazan, Kingdom of Saudi Arabia

Corresponding Author: Alhammadi MS, Department of Preventive Dental Sciences, Division of Orthodontics and Dentofacial Orthopedics, College of Dentistry, Jazan University, Jazan, Kingdom of Saudi Arabia, Phone: 00966502209874, e-mail: magedorth@yahoo.com, magedorth@gmail.com education and clinical experience gives an indication about the difference between the patients' desire and the practitioners' perception of such esthetic demands.

Keywords: Dental professionals, Facial esthetics, Layperson, Perception.

How to cite this article: Alhammadi MS. Perception of Facial Esthetics by Laypersons, Dental Assistants, General Dental Practitioners and Dental Specialists. J Contemp Dent Pract 2019;20(3):304-310.

\section{Source of support: Nil}

Conflict of interest: None

\section{INTRODUCTION}

Beauty is an overall characteristic of a person, an object or a place that reflects a perceptual experience of pleasure and/or satisfaction. Characterizing a person as "beautiful" is based on physical attractiveness owing to physical attributes which are primarily valued on an esthetic basis. In this context, one's attention is directed mainly toward the face, mouth and eyes of the person concerned. Hence, the facial attractiveness represent the most common features of human beauty. ${ }^{1}$ Generally, perception of human beauty is not an absolute issue; instead it is a relative one influenced by many factors including, but not limited to, demographic, geographic, ethnic and cultural factors. ${ }^{2}$ Apart from the subjective measures, evaluation of beautiful face is best achieved using certain beauty standards that were developed from various sources such as the measured values of a certain race, and by comparing with those who are generally considered beauteous. ${ }^{3}$

The effects of facial attractiveness may accumulate over individual's life. In other words, attractive individuals may gain influence that compounds over time into social benefits including self-confidence, 
while unattractive individuals may lose influence that compounds over time into social disadvantage. ${ }^{4}$ That is why beauty is a key motivational reason behind seeking cosmetic facial surgery, dental and/or orthodontic treatments. In general, perception of facial esthetics differs among individuals owing to many factors including experiences and social environment. ${ }^{5}$ Thus, it is essential to couple the patient's preference and needs with the esthetic features as perceived by the laypersons and dental practitioners.

Many studies evaluated laypersons' and/or dental specialist perception of specific facial esthetic characters including "facial profile", 6 "facial vertical proportions" 7,8 and "facial symmetry". 9,10 In line with that, a recent systematic review ${ }^{11}$ sought to summarize studies that assessed laypersons' and/or dental professionals' perception of different facial esthetic parameters; they search for articles evaluated facial esthetic parameters including facial profile, facial height, facial symmetry and profile lip position. So far, there has not been a study that evaluated the perception of the most important facial characteristics; facial symmetry, facial profile and facial vertical proportions collectively by laypersons and different dental professionals. Therefore, the aims of this study were to assess laypersons' and dental professionals' perception of facial symmetry, facial profile and facial height, and whether such a perception is affected by gender and dental specialty.

\section{MATERIALS AND METHODS}

\section{Study Population}

This is a cross-sectional study was performed at the College of Dentistry, Jazan University, Saudi Arabia from November 2016 to April 2017. It was approved by the Internal Review Board, college of dentistry, Jazan University. The study targeted laypersons (LP) from attendants of the college's clinics; dental assistants (DA) working in the college, general dental practitioners (GDP) working in Jazan region; and dental specialists (DS) working in the College. All participants agreed voluntarily to participate in this study.

\section{Photo Manipulation}

Three standard photograph of facial esthetics of young women were digitally modified using Adobe Photoshop software program (version CS3; Adobe Systems, Inc., San Jose, CA, USA). Each five photographs, one is the standard and four are its modified analogues, represented one group for specific esthetic trait (Figs 1 to 3 ). A visual analogue scale ranging from 1 to 5 was set to score these images, where 5 denoted the standard image and 1 denoted the least pleasant one. To sum up the overall esthetic score, the scores of the individual esthetic components' were added together and multiplied by two to be presented out of 100 (Table 1). The photographs within each group were arranged randomly and even differently in different groups.
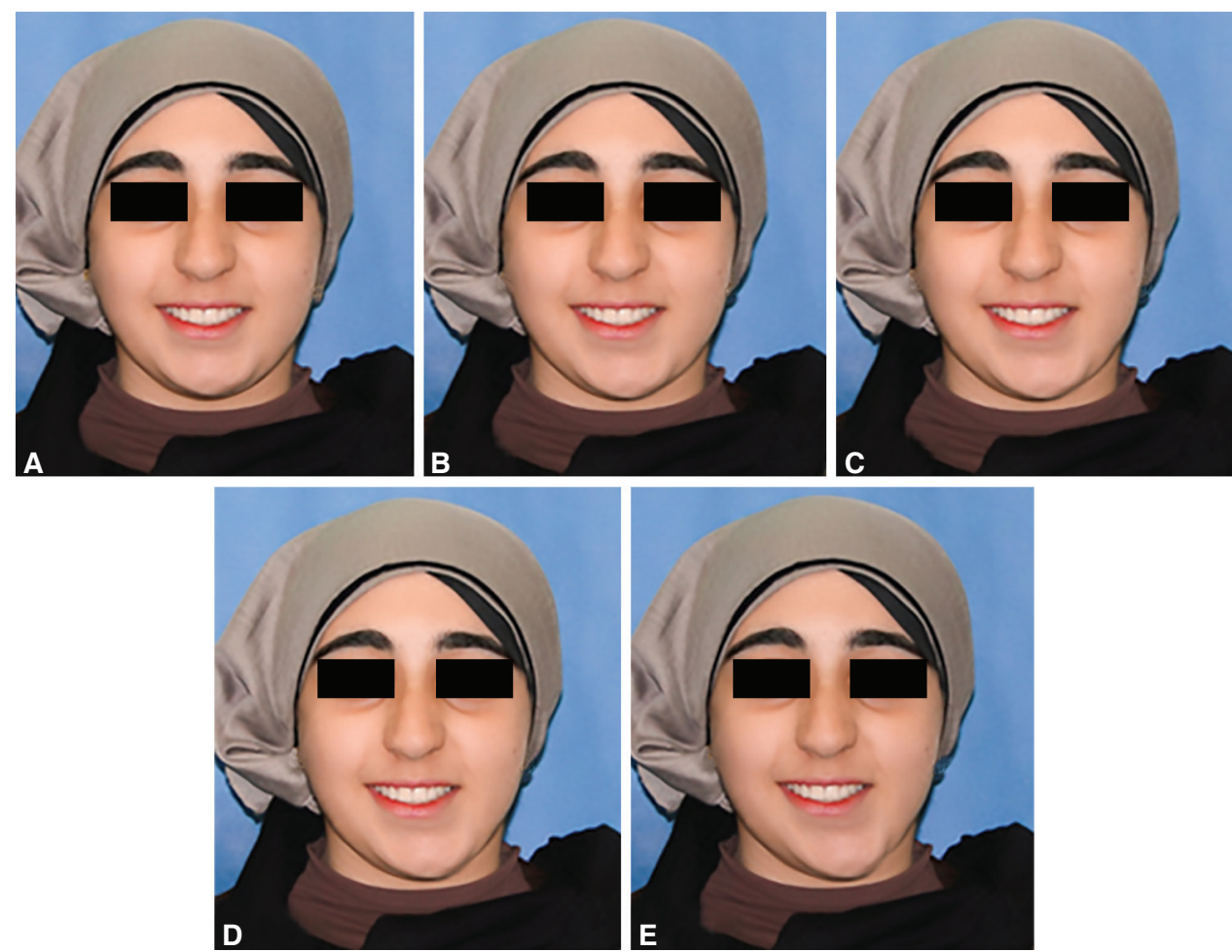

Figs 1A to E: Chin manipulations of the female with pleasant face: $(A)$ the mid-sagittal plane coincident with soft tissue pogonion point of the chin (original); (B) $2 \mathrm{~mm}$ shift of soft tissue pogonion to the left; (C) $4 \mathrm{~mm}$ shift of soft tissue pogonion to the left; (D) $6 \mathrm{~mm}$ shift of soft tissue pogonion to the left; (E) $8 \mathrm{~mm}$ shift of soft tissue pogonion to the left 

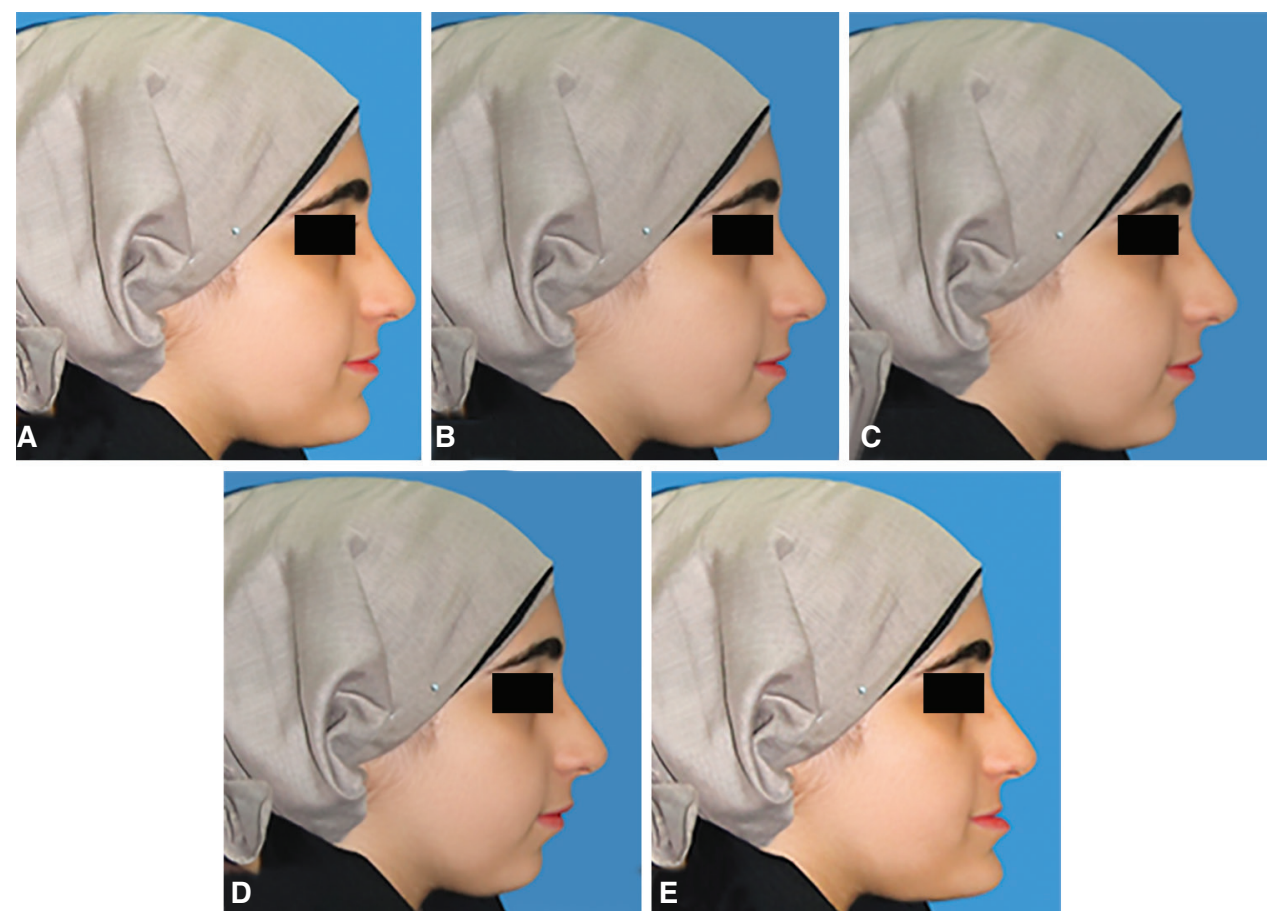

Figs 2A to E: Soft tissue profile manipulations of the female with straight profile: (A) straight facial profile (Class I) (original); (B) slightly convex facial soft tissue profile (mild Class II); (C) moderately convex facial soft tissue profile (moderate Class II); (D) severely convex facial soft tissue profile (severe Class II); (E) concave facial soft tissue profile (Class III)
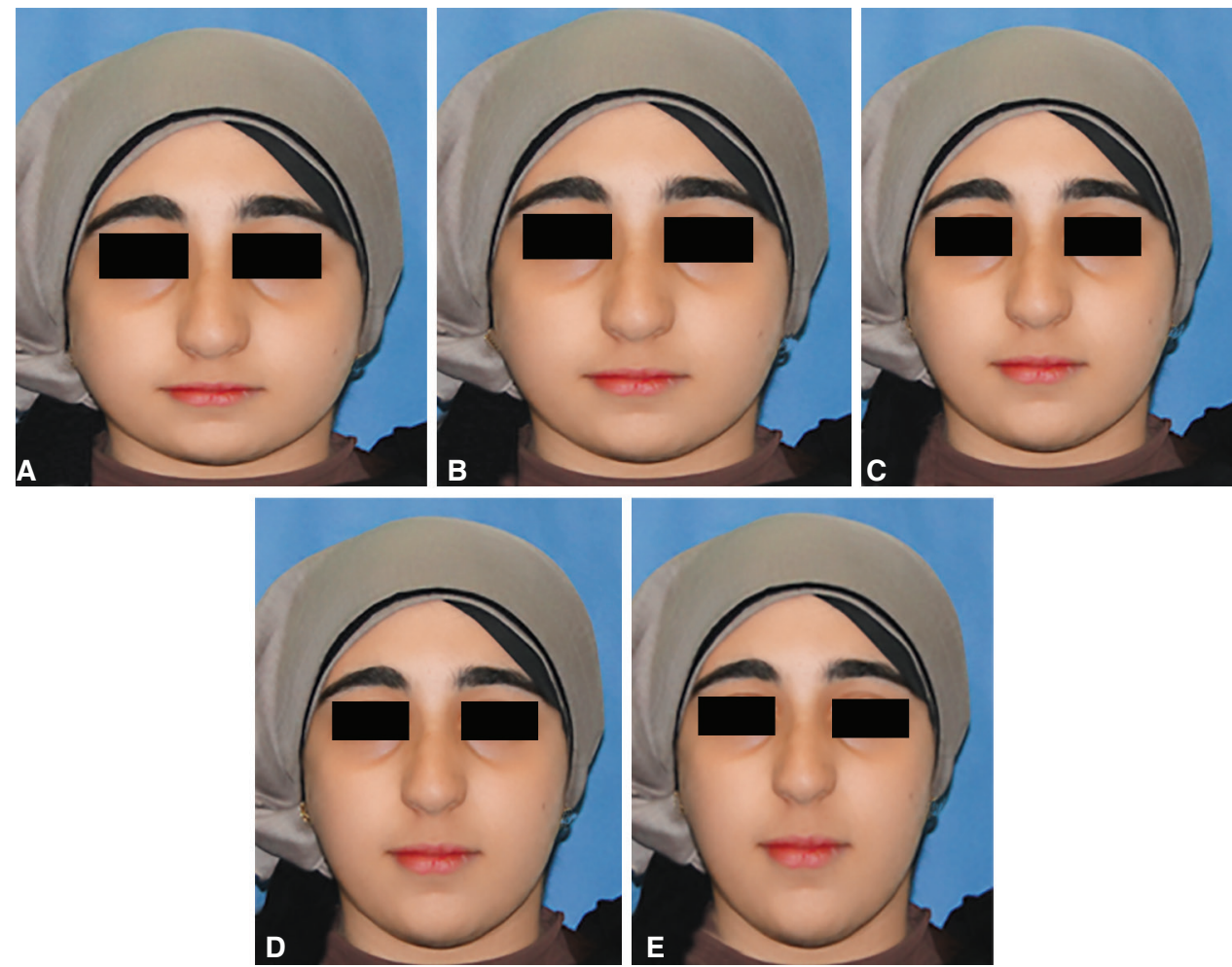

Figs 3A to E: Manipulation of facial vertical proportions: (A) severely reduced lower anterior facial height (short face); (B) slightly reduced lower anterior facial height; (C) average vertical facial proportions (original); (D) slightly increased lower anterior facial height; (E) severely increased lower anterior facial height (long face).

The above mentioned manipulation involved three facial components: (1) Facial symmetry: a photograph of a woman with a pleasant face where the mid-sagittal plane was coincident with the soft tissue pogonion point of the chin. Manipulation limited to the soft tissue pogonion point to produce a progressive facial asymmetry of $2 \mathrm{~mm}$ each [0 (standard), 2, 4, 6, and 8 mm; Figs 1 and 2) Facial soft tissue profile: a photograph of a woman with straight facial profile (skeletal class I) was manipulated to produce slightly convex, moderately convex, severely convex 
Perception of Facial Esthetics by Laypersons and Dental Professionals

Table 1: Scoring system of the perception of overall, facial symmetry, facial profile and facial vertical proportions

\begin{tabular}{ll}
\hline Variable & Score \\
\hline Overall & 100 \\
\hline Facial symmetry & 5 \\
\hline Q1 No facial asymmetry & 4 \\
2mm facial asymmetry & 3 \\
4mm facial asymmetry & 2 \\
6mm facial asymmetry & 1 \\
\hline 8mm facial asymmetry & 5 \\
\hline Q2 Straight soft tissue profile & 4 \\
Slightly convex soft tissue profile & 3 \\
Moderately convex soft tissue profile & 2 \\
Severely convex soft tissue profile & 1 \\
\hline Concave soft tissue profile & 5 \\
\hline Q3 $\quad$ Average facial vertical proportions & 4 \\
Slightly reduced anterior lower facial height & 2 \\
Short face & 3
\end{tabular}

(class II) and concave facial profile (class III) (Fig. 2), and 3) Facial vertical proportions: a photograph of a woman with average vertical facial proportion was manipulated to produce slightly reduced lower anterior facial height, short face, slightly increased lower anterior facial height and long face (Fig. 3).

\section{Data Collection}

The manipulated photos were distributed to each participant in a form of booklet composed of 3 pages. Each page represented a group of five numbered, high-resolution photographs for a given facial esthetic component as indicated above (Figs 1 to 3). The following question was put as a heading for each of these pages: "Which of the following image is the most beautiful from your point of view?" The participants answered in a pre-designed answer sheets that also included questions about participant's gender and occupation. To make sure that the booklet was presented properly, it was presented to every participant during the day light using the same color saturation and the same paper size and thickness.

To ensure a reliable assessment, ten participants were randomly selected from each occupation group and asked to assess the three groups of images twice with at least 2-week interval, the first reading was used for data analysis.

\section{Statistical Analysis}

Data were handled and analyzed using the statistical package for social sciences (SPSS) software, Version
21 (Armonk, NY: IBM Corp.). Intra-class correlation coefficients (ICC) were used for assessing the intraobserver reliability. Qualitative variables were statistically described using frequencies and proportions, and by means with standard deviations and medians with interquartile ranges (IQR) for quantitative variables. Individual (out of 5) and overall (out of 100) esthetic scores were checked for normal distribution using Kolmogorov-Smirnov test. Between-group comparisons, based on gender and occupation, were done using Kruskal-Wallis test followed by pairwise comparisons.

Stepwise multiple linear regression analyses were conducted to determine the significant independent determinants of perception of individual and overall esthetics; the gender and occupation were entered into the equations as independent variables. A $p$ value of $<0.05$ was considered significant.

\section{RESULTS}

There were 465 participants of which 237 (51\%) were males. A hundred forty two (30.5\%) were laypersons, 97 (20.9\%) were dental assistants, 152 (32.7\%) were general dental practitioners and $74(15.9 \%)$ were dental specialists (Table 2).

The results of intra-observer reliability showed a very good agreement; 0.986 for facial symmetry, 0.801 for both facial profile and facial vertical proportions.

The overall mean score of facial esthetic perception was almost good $(61.29 \pm 16.19)$ with no gender difference. The highest perception was reported for "facial vertical 
Table 2: Characteristics of the participants of the study

\begin{tabular}{lllll}
\hline Category & $\begin{array}{l}\text { Males } \\
n(\%)\end{array}$ & $\begin{array}{l}\text { Females } \\
n(\%)\end{array}$ & $\begin{array}{l}\text { Total } \\
N(\%)\end{array}$ & $p$ value \\
\hline Laypersons & $68(28.6)$ & $74(32.5)$ & $142(30.5)$ & $<0.001$ \\
Dental assistants & $37(15.6)$ & $60(26.3)$ & $97(20.9)$ & \\
General dental practitioners & $80(33.8)$ & $72(31.6)$ & $152(32.7)$ & \\
Dental specialists & $52(21.9)$ & $22(9.6)$ & $74(15.9)$ & \\
\hline Total & $237(51)$ & $228(49)$ & $465(100)$ & \\
\hline
\end{tabular}

Table 3: Mean and median scores of perception of facial symmetry, facial profile and facial vertical proportions for the whole sample and by gender

\begin{tabular}{|c|c|c|c|c|c|c|c|}
\hline \multirow[b]{2}{*}{ Esthetic components } & \multicolumn{2}{|c|}{ All sample $(N=465)$} & \multicolumn{2}{|c|}{ Males $(n=237)$} & \multicolumn{2}{|c|}{ Females $(n=228)$} & \multirow[b]{2}{*}{$p$ value } \\
\hline & Mean (SD) & $\begin{array}{l}\text { Median } \\
\text { (IQR) }\end{array}$ & Mean (SD) & $\begin{array}{l}\text { Median } \\
(I Q R)\end{array}$ & Mean (SD) & $\begin{array}{l}\text { Median } \\
\text { (IQR) }\end{array}$ & \\
\hline Overall & $\begin{array}{l}61.29 \\
(16.19)\end{array}$ & $\begin{array}{l}60 \\
(46.6-73.3)\end{array}$ & $\begin{array}{l}61.06 \\
(15.77)\end{array}$ & $\begin{array}{l}60 \\
(50-73.3)\end{array}$ & $\begin{array}{l}61.52 \\
(16.65)\end{array}$ & $\begin{array}{l}66.6 \\
(46.6-73.3)\end{array}$ & 0.539 \\
\hline Q1 (facial symmetry) & $2.98(1.35)$ & $3(2-4)$ & $3.12(1.32)$ & $3(2-4)$ & $2.83(1.37)$ & $3(2-4)$ & 0.018 \\
\hline Q2 (facial profile) & $3.45(1.19)$ & $4(3-4)$ & $3.32(1.14)$ & $3(3-4)$ & $3.57(1.23)$ & $4(3-5)$ & 0.014 \\
\hline $\begin{array}{l}\text { Q3 (facial vertical } \\
\text { proportions) }\end{array}$ & $4(1.31)$ & $5(3-5)$ & $4.14(1.25)$ & $5(4-5)$ & $3.86(1.36)$ & $4(3-5)$ & 0.019 \\
\hline
\end{tabular}

IQR: Interquartile range

Table 4: Mean and median scores of sample perception of facial symmetry, facial profile, facial vertical proportions and overall facial esthetic by participant's category

\begin{tabular}{|c|c|c|c|c|c|c|c|c|c|}
\hline \multirow[b]{2}{*}{$\begin{array}{l}\text { Esthetic } \\
\text { components }\end{array}$} & \multicolumn{2}{|c|}{$\begin{array}{l}\text { Layperson } \\
(n=142)\end{array}$} & \multicolumn{2}{|c|}{$\begin{array}{l}\text { Dental assistant } \\
(n=97)\end{array}$} & \multicolumn{2}{|c|}{$\begin{array}{l}\text { General dental } \\
\text { practitioner } \\
(n=152)\end{array}$} & \multicolumn{2}{|c|}{$\begin{array}{l}\text { Dental specialist } \\
(n=74)\end{array}$} & \multirow[b]{2}{*}{$p$ value } \\
\hline & $\begin{array}{l}\text { Mean } \\
(S D)\end{array}$ & $\begin{array}{l}\text { Median } \\
\text { (IQR) }\end{array}$ & $\begin{array}{l}\text { Mean } \\
(S D)\end{array}$ & $\begin{array}{l}\text { Median } \\
\text { (IQR) }\end{array}$ & $\begin{array}{l}\text { Mean } \\
(S D)\end{array}$ & $\begin{array}{l}\text { Median } \\
(I Q R)\end{array}$ & $\begin{array}{l}\text { Mean } \\
(S D)\end{array}$ & $\begin{array}{l}\text { Median } \\
\text { (IQR) }\end{array}$ & \\
\hline Overall & $\begin{array}{l}61.17 \\
(15.8)\end{array}$ & $\begin{array}{l}60 \\
(51.6- \\
73.3)\end{array}$ & $\begin{array}{l}59.38 \\
(18.38)\end{array}$ & $\begin{array}{l}60 \\
(46.6-73.3)\end{array}$ & $\begin{array}{l}62.54 \\
(15.18)\end{array}$ & $\begin{array}{l}66.6 \\
(53.3- \\
73.3)\end{array}$ & $\begin{array}{l}61.44 \\
(15.88)\end{array}$ & $\begin{array}{l}60 \\
(51.6- \\
73.3)\end{array}$ & 0.518 \\
\hline $\begin{array}{l}\text { Q1 } \\
\text { (facial } \\
\text { symmetry) }\end{array}$ & $\begin{array}{c}2.73 \\
(1.38)\end{array}$ & $2(2-4)^{a}$ & $\begin{array}{l}2.82 \\
(1.22)\end{array}$ & $3(2-4)^{a}$ & $\begin{array}{l}3.32 \\
(1.35)\end{array}$ & $3(2-5)^{b}$ & $\begin{array}{l}2.97 \\
(1.35)\end{array}$ & $3(2-4)^{a, b}$ & 0.001 \\
\hline $\begin{array}{l}\text { Q2 } \\
\text { (facial profile) }\end{array}$ & $\begin{array}{c}3.27 \\
(1.29)\end{array}$ & $3(2-4)$ & $\begin{array}{c}3.58 \\
(1.14)\end{array}$ & $4(3-4)$ & $\begin{array}{l}3.55 \\
(1.11)\end{array}$ & $4(3-4)$ & $\begin{array}{l}3.41 \\
(1.19)\end{array}$ & $3(3-4)$ & 0.268 \\
\hline $\begin{array}{l}\text { Q3 } \\
\text { (facial vertical } \\
\text { proportions) }\end{array}$ & $\begin{array}{l}3.5 \\
(1.41)\end{array}$ & $4(2-5)^{a}$ & $\begin{array}{c}3.89 \\
(1.32)\end{array}$ & $4(3-5)^{a}$ & $\begin{array}{l}4.64 \\
(0.9)\end{array}$ & $5(5-5)^{b}$ & $\begin{array}{l}3.81 \\
(1.31)\end{array}$ & $4(3-5)^{a}$ & $<0.001$ \\
\hline
\end{tabular}

IQR: interquartile range.

Within the same raw different superscript letters over the medians (IQR) are statistically different.

proportions" ( $4 \pm 1.31)$ followed by "facial profile" (3.45 \pm 1.19 ), while the lowest perception was reported for "facial symmetry" ( $2.98 \pm 1.35)$. Males perceived "facial symmetry" and "facial vertical proportions" more precisely than females did $(p<0.05$ each) while females significantly perceived "facial profile" more precisely than males did $(p<0.05$ each; Table 3$)$.

The results of the effect of occupation/specialty on the perception of facial esthetics are presented in Table 4. The mean score of overall perception was insignificant between all categories. Pairwise comparisons with regard to the perception of different facial esthetic components revealed no significant differences between LP, DA, GDP and DS in perception of "facial profile". With regard to the facial vertical proportions, the highest scores were reported for the GDP followed by DA, DS and LP with a few statistical differences between them. For the facial symmetry, the highest scores were reported for the GDP followed by DS, DA and LP with a few statistical differences between them.

Multiple linear regressions confirmed the bivariate analyses; Professionals' category and gender were differentially and variably independent determinants of facial esthetic perception although the role of the professionals' category was more obvious in most of the facial esthetic components. However, the fractions 
Perception of Facial Esthetics by Laypersons and Dental Professionals

Table 5: Independent determinants of sample perception of facial symmetry, facial profile and facial vertical proportions as shown by stepwise multiple linear regression analyses

\begin{tabular}{|c|c|c|c|c|}
\hline Determinants & $B$ & $\mathrm{Cl} 95 \%$ of $B$ & Adjusted $R^{2}$ & $p$ value \\
\hline \multicolumn{5}{|c|}{ Facial components } \\
\hline \multicolumn{5}{|l|}{ Q1 (facial symmetry) } \\
\hline Participant's category & 0.0146 & $0.031-0.26$ & 0.015 & 0.013 \\
\hline Gender & -0.253 & $-0.5--0.007$ & 0.021 & 0.044 \\
\hline \multicolumn{5}{|l|}{ Q2 (facial profile) } \\
\hline Gender & 0.25 & $0.034-0.466$ & 0.009 & 0.024 \\
\hline \multicolumn{5}{|c|}{ Q3 (facial vertical proportions) } \\
\hline Participant's category & 0.26 & $0.152-0.369$ & 0.043 & $<0.001$ \\
\hline
\end{tabular}

The independent variables which entered into the models were: gender and occupation. Gender was coded as: 1 for male and 2 for female; Participant's category was coded as: 1 for layperson, 2 for dental assistant, 3 for general dental practitioner and 4 for dental specialist.

by which these two variables contributed into the explanation of the variability of facial esthetic perception were minimal ranging from as low as $\mathrm{R}^{2}$ of $0.009 \%$ (facial profile) to $\mathrm{R}^{2}$ of 0.043 (facial vertical proportions) (Table 5).

\section{DISCUSSION}

Facial esthetic perception is of a paramount importance in dental practice. Supposedly, with dental education and/or experience, there must be tiny variations in perception of facial esthetics. However, this was not the case in our study where there were remarkable variations among different dental professionals although they perceived these components more precisely when compared to LP.

In a recent systematic review, Barbosa et al. ${ }^{11}$ conducted their review in four databases; aimed to assess whether dentists are more critical in assessing facial esthetics than laypersons. Three relevant articles ${ }^{12-14}$ were selected from an initial total of 979 articles collected. They concluded that due to the methodological diversity of the studies, it was not possible to establish a valid result and could not be concluded whether dentists are indeed more critical in the photographic assessment of facial esthetics. They suggested "Further studies with more standardized methods are suggested in order to definitely clarify who is more critical in the subjective assessment of facial characteristics". ${ }^{11}$ To the best of our knowledge, this is the first study that assessed all facial esthetic components once and among a large sample of individuals who had different dental education and clinical experience. The maximum number of raters in their study was $30,{ }^{14}$ while the minimum number of raters in this study is 74 (Dental Specialists).

The overall perception of esthetics by the whole sample was almost good $(61.29 \pm 16.19$ out of 100$)$ with no gender differences. All facial characteristics perceived differently by both genders. Males perceived "facial symmetry" and "facial vertical proportions" more precisely than females did although this is contradictory to the results reported by McAvincheya et al. ${ }^{10}$ and Soni et al. ${ }^{7}$ which indicated that gender of the observer had no influence on perception of "facial symmetry" and "facial vertical proportions", respectively. This contradiction might be due to the difference in the level of dental experience of the raters as in their study the rater were either laypersons or orthodontists. In contrary, females perceived "facial profile" more precisely than males did. Such a result is in agreement with the finding of $\mathrm{Abu}$ Alhaija et al. ${ }^{15}$ and Yin et al. ${ }^{6}$

With regard to the participants' occupations, the overall perception was not significant amongst all occupations. When comes to the individual facial esthetic components, most of GDP were found to perceive "facial asymmetry" when between 0-6 mm while LP and DA were found to perceive the same component between 2-6 mm. McAvinchey et al. ${ }^{10}$ reported that LP perceived "facial asymmetry" if above 3 up to $8 \mathrm{~mm}$ while orthodontist perceived it as abnormal if between 2-5 $\mathrm{mm}$.

There were no significant differences between groups regarding perception of "facial profile." Most of the participants favored slightly convex and moderately convex facial profile. Yin et al. ${ }^{6}$ reported that about $85 \%$ of the LP, in comparison to $37 \%$ of orthodontists, prefer the straight facial profile, while the rest favored the convex facial profile.

With regard to the other facial vertical proportions, more GDP perceived average facial vertical height as the preferred "facial form" than the other groups of participants. Most of LP, DA and DS favored average, slightly increased and slightly reduced facial vertical height. This means that most of the sample preferred average and the borderlines average vertical facial pattern. Abu Arqoub ${ }^{16}$ found that the average and the reduced lower facial height was the most preferred profile in their study. A similar result was reported by Japanese population. ${ }^{8}$ 
Facial esthetics was perceived differently by both genders; males were more sensitive in perceiving such changes than females. General dental practitioners perceived more than layperson or others in dental field; this might be due to their exposure to variety of cases than others did.

One limitation of this study was small sample size of each dental specialty making intergroup comparisons invalid. Another limitation was the variation in number of males and females for dental assistants and dental specialists.

\section{CONCLUSION}

- The overall facial esthetic perception was almost high with no gender differences.

- Most of the facial esthetic components were perceived differently in favor of the GDP followed by DS; the lowest perception scores were for LP.

\section{REFERENCES}

1. Van der Geld P, Oosterveld P, Van Heck G, et al. Smile attractiveness. Self-perception and influence on personality. Angle Orthod 2007;77:759-765.

2. Broer PN, Juran S, Liu YJ, et al. The impact of geographic, ethnic, and demographic dynamics on the perception of beauty. J Craniofac Surg 2014;25:e157-161.

3. de Deus Tupinambá Rodrigues $C$, et al. The perception of smile attractiveness: variations from esthetic norms, photographic framing and order of presentation. The Angle Orthod 2009;79:634-639.

4. Anderson C, John OP, Keltner D, et al. Who attains social status? Effects of personality and physical attractiveness in social groups. J Pers Soc Psychol 2001;81:116-132.
5. Flores-Mir C, Silva E, Barriga MI, et al. Lay person's perception of smile aesthetics in dental and facial views. J Orthod 2004;31:204-209; discussion 201.

6. Yin L, Jiang $M, C$ hen $W$, et al. Differences in facial profile and dental esthetic perceptions between young adults and orthodontists. Am J Orthod Dentofacial Orthop 2014;145: 750-756.

7. Soni J, Shyagali T, Kulkarni N, et al. Evaluation of influence of altered lower vertical proportions in the perception of facial attractiveness. Int J Orthod Rehabil 2016;7:124.

8. Ioi H, Yasutomi H, Nakata S, et al. Effect of lower facial vertical proportion on facial attractiveness in Japanese. Orthod Waves 2006;65:161-165.

9. Silva BP, Jimenez-Castellanos E, Martinez-de-Fuentes R, et al. Laypersons' perception of facial and dental asymmetries. Int J Periodontics Restorative Dent 2013;33:e162-171.

10. McAvinchey G, Maxim F, Nix B, et al. The perception of facial asymmetry using 3-dimensional simulated images. Angle Orthod 2014;84:957-965.

11. Barbosa PBC, de Souza Matos F, Cericato GO, Rosário HD, et al. Perception of laypersons and dentists regarding esthetic facial changes: a systematic review. Bioscience J 2016;32.

12. Fabré M, Mossaz C, Christou P, et al. Orthodontists' and laypersons' aesthetic assessment of Class III subjects referred for orthognathic surgery. Eur J Orthod 2009;31:443-448.

13. Torsello F, Graci M, Grande NM, et al. Relationships between facial features in the perception of profile attractiveness. Prog Orthod 2010;11:92-97.

14. Silva NCFd, Aquino ÉRBd, Mello KCFR, et al. Orthodontists' and laypersons' perception of mandibular asymmetries. Dental Press J Orthod 2011;16:38. e31-38. e38.

15. Alhaija ESA, Al-Shamsi NO, Al-Khateeb S. Perceptions of Jordanian laypersons and dental professionals to altered smile aesthetics. Eur J Orthod 2011;33:450-456.

16. Abu Arqoub SH, Al-Khateeb SN. Perception of facial profile attractiveness of different antero-posterior and vertical proportions. Eur J Orthod 2010;33:103-111. 